\title{
Effects of surface current-wind interaction in an eddy-rich general ocean circulation simulation of the Baltic Sea
}

\author{
Heiner Dietze and Ulrike Löptien \\ GEOMAR, Helmholtz Centre for Ocean Research Kiel, Düsternbrooker Weg 20, 24105 Kiel, Germany \\ Correspondence to: Heiner Dietze (hdietze@geomar.de)
}

Received: 29 February 2016 - Published in Ocean Sci. Discuss.: 23 March 2016

Revised: 19 July 2016 - Accepted: 21 July 2016 - Published: 18 August 2016

\begin{abstract}
Deoxygenation in the Baltic Sea endangers fish yields and favours noxious algal blooms. Yet, vertical transport processes ventilating the oxygen-deprived waters at depth and replenishing nutrient-deprived surface waters (thereby fuelling export of organic matter to depth) are not comprehensively understood. Here, we investigate the effects of the interaction between surface currents and winds on upwelling in an eddy-rich general ocean circulation model of the Baltic Sea. Contrary to expectations we find that accounting for current-wind effects inhibits the overall vertical exchange between oxygenated surface waters and oxygendeprived water at depth. At major upwelling sites, however (e.g. off the southern coast of Sweden and Finland) the reverse holds: the interaction between topographically steered surface currents with winds blowing over the sea results in a climatological sea surface temperature cooling of $0.5 \mathrm{~K}$. This implies that current-wind effects drive substantial local upwelling of cold and nutrient-replete waters.
\end{abstract}

\section{Introduction}

A century ago, Taylor et al. (1916) proposed that the stress describing the exchange of momentum between a moving atmosphere and the earth's surface may be expressed as being proportional to the wind speed squared times the density of air. As for the respective proportionality constant, often referred to as the drag coefficient, Taylor et al. (1916) calculated values between 0.002 and 0.003 "for the ground at Salisbury Plain, where the wind observations were made".

Numerous studies, targeted at improving the fidelity of this seminal relationship for oceanic applications, have been published ever since, among them those exploring the depen- dency of the drag coefficient on (a) wind speed (e.g. Smith and Banke, 1975), (b) atmospheric stability (e.g. Hsu, 1974), and (c) wind-wave interaction (e.g. Hsu, 1973). Even so, the transfer of momentum from the atmosphere to the ocean is still associated with considerable uncertainties. For example, data assimilation experiments suggest that recent surface stress estimates may be substantially altered within their "accepted" uncertainty in order to reconcile in situ observations with circulation models (Stammer et al., 2004; Köhl et al., 2007). To this end, it is somewhat conspicuous that the respective wind stress corrections are especially large in regions of strong surface currents such as in the Gulf Stream, Kuroshio, Leeuwin Current, and the Antarctic Circumpolar Current. The conclusion that the drag coefficient is substantially influenced by strong ocean currents is, however, supposedly wrong (Kara et al., 2007).

In contrast to ongoing controversial discussions on the drag coefficient, there is now consensus that the calculation of the stress, exerted by the wind on a circulating ocean, should be based on the wind vectors relative to the ocean currents - rather than being based on the wind vectors only (Fairall et al., 2003). This may be surprising given the rather high uncertainties of the drag coefficient (discussed above), and that ocean currents are typically orders of magnitudes smaller than atmospheric winds which - in turn - suggests that the neglect of the (slow) movement of the ocean's surface should not alter the stress calculation significantly within its already-substantial uncertainty. Martin and Richards (2001) building on Dewar and Flierl (1987) put forward a striking argument to consider the ocean's movement at the surface in the stress calculation nonetheless. It is based on the concept of Ekman pumping. Ekman pumping is considered a major agent via which the atmosphere 
drives the general oceanic circulation (Stommel, 1957) and it is key to our understanding of how energy is transferred into the interior ocean (e.g. Roquet et al., 2011). Ekman pumping depends on the curl of the wind stress, which is composed of spatial derivatives - and thus comes the relevance of ocean surface currents: oceanic currents typically vary on spatial scales that are much smaller than the winds associated with relatively large-scale atmospheric weather systems. So the argument here is that, in terms of their effect on Ekman pumping which is a major control on circulation, ocean surface currents compensate for their rather weak magnitude by relatively large changes on small spatial scales.

The study of Martin and Richards (2001) includes a drastic demonstration of this effect. The authors argue that even a spatially uniform wind blowing over an ocean eddy should yield significant wind stress curls and an associated vertical Ekman pumping of the order of $\approx 0.5 \mathrm{~m} \mathrm{~d}^{-1}$ in typical open-ocean conditions. Direct observations of this so-dubbed eddy-wind effect in a North Atlantic eddy by McGillicuddy et al. (2007) and Ledwell et al. (2008) confirmed both the existence of the process and its magnitude. The associated local effects on marine biota were so pronounced that the authors speculated that the, hitherto unaccounted, eddy-wind effect could resolve a long-standing discrepancy between nutrient supply to and oxygen consumption below the euphotic zone of the subtropical gyre (e.g. Oschlies et al., 2003; Dietze and Oschlies, 2005; Kähler et al., 2010). This, however, has been discussed controversially by Eden and Dietze (2009).

This study sets out to constrain the large-scale effects of surface current-wind interaction in the Baltic Sea, a marginal sea in central northern Europe where eddy-wind effects should be especially prominent: as explained above, the spacial scales of surface currents are key to the magnitude of the effect. Rough scaling suggests that an energetic prevalent spacial scale of oceanic circulation is the Rossby radius of deformation. In typical mid-latitude open-ocean conditions (such as explored by Eden and Dietze, 2009) the first baroclinic Rossby radius is of the order of $50 \mathrm{~km}$ and the associated eddy-wind effect would be of the order of $\approx 0.5 \mathrm{~m} \mathrm{~d}^{-1}$, as explained above. In the Baltic Sea, however, affected by shallower water depths and strong stratification, the Rossby radii are typically an order of magnitude smaller (1.3 to $7 \mathrm{~km}$, Fennel et al., 1991), which in turn suggests that eddy-wind effects are an order of magnitude stronger than in the open ocean. If so, this effect should be a major process in the Baltic, affecting vertical exchange between the welloxygenated surface waters and the dense oxygen-depleted deep waters. As such, surface current-wind effects should rank among the first-order processes controlling the intermittent deoxygenation of the Baltic Sea, which endangers fish yields and favours noxious algal blooms.

So far, surface current-wind effects have not been explicitly investigated in the Baltic. Among the reasons are the small Rossby radii in the Baltic, which call for much higher horizontal resolution and associated computational cost than is the case for open-ocean model studies. It is only recently that advances in compute hardware have rendered this feasible.

This paper sets out to explore current-wind effects in the Baltic with the recently developed high-resolution general ocean circulation model configuration MOMBA 1.1 (Dietze et al., 2014). Section 2 describes the model configuration and the numerical experiments. Section 3 presents model results followed by a discussion in Sect. 4 . We close with a summary and conclusions in Sect. 5.

\section{Method}

We conduct a numerical twin experiment with the general circulation ocean model configuration MOMBA 1.1 (Dietze et al., 2014): the reference simulation REF includes the surface current-wind effect while the other simulation noCW (short for no current-wind effect) does not account for this effect. A major difference compared to previous studies that cover the western Mediterranean (Olita, 2015) and the North Atlantic (Eden and Dietze, 2009) is our focus on the shallow Baltic Sea where, as outlined above, current-wind effects should be most prominent.

\subsection{Model configuration}

All experiments are based on a regional ocean-ice model setup of the Baltic Sea, called MOMBA 1.1. The configuration is extensively documented in Dietze et al. (2014), and accessible via www.baltic-ocean.org. The model features a horizontal resolution of $\approx 1.9 \mathrm{~km}$ corresponding to one nautical mile; it is eddy-rich in that it starts to resolve the relevant spacial scales (cf. Fennel et al., 1991). The model domain is bounded by 4.2 and $30.3^{\circ} \mathrm{E}$ and 53.8 to $66^{\circ} \mathrm{N}$. The vertical discretization comprises 47 levels. There are no open boundaries: the model domain is surrounded by solid walls. We use the $K$ profile parameterization (KPP, Large et al., 1994) with parameters identical to those applied in the eddypermitting global configurations of Dietze and Kriest (2012), Dietze and Löptien (2013), and Liu et al (2010). The atmospheric boundary conditions driving MOMBA 1.1 are based on dynamically downscaled ERA-40 reanalysis data (Uppala et al., 2005). The respective downscaling is performed by the Rossby Centre Regional Atmosphere model version 3 (hereafter RCA3), which takes ERA-40 reanalysis data as boundary conditions. RCA3 features an enhanced (relative to ERA-40) horizontal resolution of $25 \mathrm{~km}$ (Jones et al., 2004; Samuelsson et al., 2011). These atmospheric boundary conditions are identical to those applied to the "RCO" models, used, e.g. by Hordoir et al. (2013), Löptien et al. (2013), and Meier and Faxen (2002).

Results from a 1987 to 1999 hindcast simulation showcased in Dietze et al. (2014) illustrate that the model's fidelity is competitive with other Baltic Sea models. Remark- 
ably, MOMBA 1.1 simulates very realistic sea surface temperatures, which is indicative of a correct representation of near-surface diabatic processes.

\subsection{Experiments}

In the following Sect. 3, we compare two numerical experiments, REF and noCW. REF refers to the reference simulation including the surface current-wind effect, while the other simulation, noCW, does not account for the currentwind effect. The simulation REF is based on the exact same MOMBA 1.1 configuration described in Dietze et al. (2014). REF has, in contrast to previously published Baltic Sea models (e.g. Meier et al., 1999, 2012; Meier and Faxen, 2002), a better representation of the feedback of ocean surface currents, $\boldsymbol{u}_{\mathrm{o}}$, on the wind stress, $\boldsymbol{\tau}_{\text {ref }}$, because (a) it explicitly accounts for ocean currents in the calculation of the wind stress as recommended by e.g. Large and Yeager (2004) and Fairall et al. (2003), and (b) in contrast to the previous generation of ocean circulation models, MOMBA 1.1 features a relatively high horizontal resolution of 1 nautical mile, which starts to resolve mesoscale processes in the Baltic.

The stress $\boldsymbol{\tau}_{\text {ref }}$ exerted on the ocean's surface by winds blowing with a velocity $\boldsymbol{u}_{\mathrm{a}}$ over an oceanic current moving with a velocity $\boldsymbol{u}_{0}$ is calculated in experiment REF as

$\boldsymbol{\tau}_{\text {ref }}=\rho_{\mathrm{a}} c_{\mathrm{D}}\left|\boldsymbol{u}_{\mathrm{a}}-\boldsymbol{u}_{\mathrm{o}}\right|\left(\boldsymbol{u}_{\mathrm{a}}-\boldsymbol{u}_{\mathrm{o}}\right)$,

with the density of air $\rho_{\mathrm{a}}$ and the dimensionless drag coefficient $c_{\mathrm{D}}$. Note that $c_{\mathrm{D}}$ is not constant, as we apply the formulation detailed in Large and Yeager (2004) and Large (2006).

The setup noCW does not include the effects of surface current-wind interaction. Other than that it is identical to the setup REF. More specifically, the stress $\boldsymbol{\tau}_{\text {noCW }}$ exerted on the ocean's surface in experiment noCW is calculated (similar to, e.g., Meier et al., 1999, their Eq. 30) as

$\boldsymbol{\tau}_{\boldsymbol{n o C} \boldsymbol{W}}=\rho_{\mathrm{a}} c_{\mathrm{D}}\left|\boldsymbol{u}_{\mathrm{a}}\right| \boldsymbol{u}_{\mathrm{a}}$.

Both simulations start from rest on 1 January 1987 and are integrated till 31 December 1993. In the following analysis we explore the model output starting from 1 January 1988 thus allowing for a 1-year spin-up phase. We stop the simulation on 31 December 1993, which constrains the period to one where the models compare especially favourably to observations. Contrary to Dietze et al. (2014) we compile the Fortran model code with ifort version 14.0.0 using nonaggressive compiler options (-msse4.2, -i4, -r8, and align all). This ensures that the differences discussed here are due to actually differing model formulations rather than being caused by "computational uncertainty" (cf. Sect. 3.8 in Dietze et al., 2014).

\section{Results}

One major focus here is on simulated sea surface temperatures (SSTs) and causes of SST differences in the simula- tions REF and noCW. We argue that SST is prominent because (1) it controls the velocity of biogeochemical turnover in the sunlit surface, as e.g. enzyme-catalysed reactions feature a sensitivity corresponding to roughly $10 \%$ increase per kelvin increase. (2) SST controls sea fog. The latter is of interest since the Baltic hosts up to $15 \%$ of the world's international maritime cargo (HELCOM , 2009) and because around $10 \%$ of all collisions are apparently related to sea fog (Tuovinen et al., 1984). (3) SST variation is a proxy for diabatic processes. Consequently, simulated SST differences can be related to differing nutrient transports to the sunlit surface, associated export of organic matter to depth, and oxygen consumption at depth.

\subsection{Basin-scale effects}

The upper two panels in Fig. 1 show seasonal cycles of simulated basin-averaged SSTs and air-sea heat fluxes in the simulation REF. During boreal summer the Baltic is heated up to $\approx 18^{\circ} \mathrm{C}$ and cooled down to almost $0^{\circ} \mathrm{C}$ in winter. The third panel in Fig. 1 shows that the amplitude of the seasonal cycle in air-sea heat fluxes is reduced when accounting for surface current-wind effects. At the same time the seasonal amplitude in SSTs increases (lowermost panel in Fig. 1). Hence, our simulations show that surface-current-wind effects drive increased SST warming (cooling) in summer (winter), even though air-sea heat fluxes supply less heat (less cooling). From this, we conclude that the diabatic exchange of heat is reduced by current-wind effects - or, in other words, the summer time warming (winter time cooling) is distributed over a shallower water column such that it results in an increased amplitude of the seasonal SST cycle. This conclusion is contrary to expectations outlined in the introduction: due to the anticipated strong eddy wind interactions, we would rather have expected an increase in basin-scale diabatic transports and, consequently, a reduced amplitude of the basinscale seasonal SST cycle. As this does not apply other counteracting mechanisms must prevail on large scales.

The reduced diabatic transports associated with currentwind effects become reasonable when considering the transfer of kinetic energy to the ocean. We argue that accounting for the ocean's movement in the calculation of wind stress exerted on the ocean's surface, overall less energy is transferred to the ocean because a combination of the following conditions are on hand: (1) surface currents may be aligned perpendicular to the wind, which yields neither increased nor decreased stress exerted on the ocean's surface; (2) surface currents may oppose the winds such that the ocean's movement is slowed down with the current-wind effect accelerating the oceanic energy drain; and (3) surface currents may run along with the winds such that the current-wind effect reduces the drag, so less momentum and energy is transferred to the ocean. Thus, depending on the direction of the wind relative to the surface currents, the local contemporary en- 

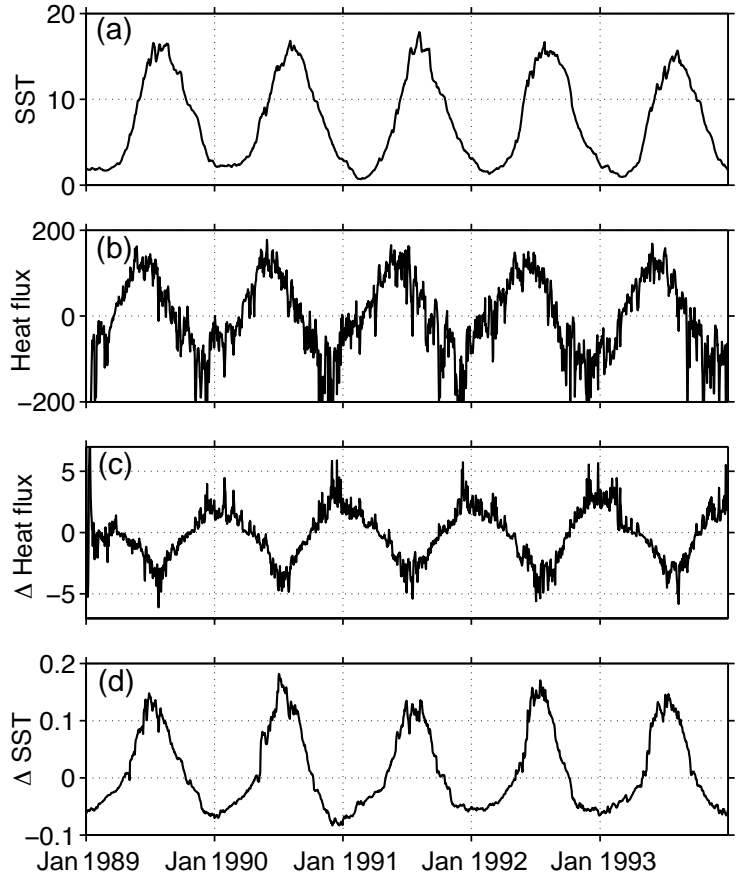

Figure 1. Basin-scale averaged temporal evolution of (a) sea surface temperature (upper panel, units ${ }^{\circ} \mathrm{C}$ ), (b) air-sea heat fluxes (second panel, units $\mathrm{W} \mathrm{m}^{-2}$ ), (c) air-sea heat flux differences (third panel, units $\mathrm{W} \mathrm{m}^{-2}$ ), and (d) sea surface temperature differences (lowermost panel, units $\mathrm{K}$ ). The differences $\Delta$ are calculated as experiment REF - noCW. Positive (negative) $\Delta$ heat flux values denote reduced cooling (warming) in winter (summer) by surface current-wind effects. Likewise, positive $\Delta$ SST (negative) values indicate warming (cooling) by surface current-wind effects.

ergy transfer is either unchanged or decreased, but never increased.

Figure 2 confirms the reduced energy transfer showing that in experiment REF the net basin-scale energy transfer by winds is less than in experiment noCW. This reduced net transfer of kinetic energy yields weaker surface currents and, consequently, weaker vertical shear of horizontal velocities. This, in turn, reduces shear-induced turbulent mixing. Consistent with this argument we find, on basin-scale average, shallower surface mixed layers in experiment REF: Fig. 3 shows the simulated differences in summer. The differences in winter have the same sign but are 1 order of magnitude larger (not shown). Basin-scale shallower surface mixed layers result in the reduced "thermal momentum" of that surface layer (which is in contact with the atmosphere) and result, as described above, in higher (lower) SSTs in summer (winter).

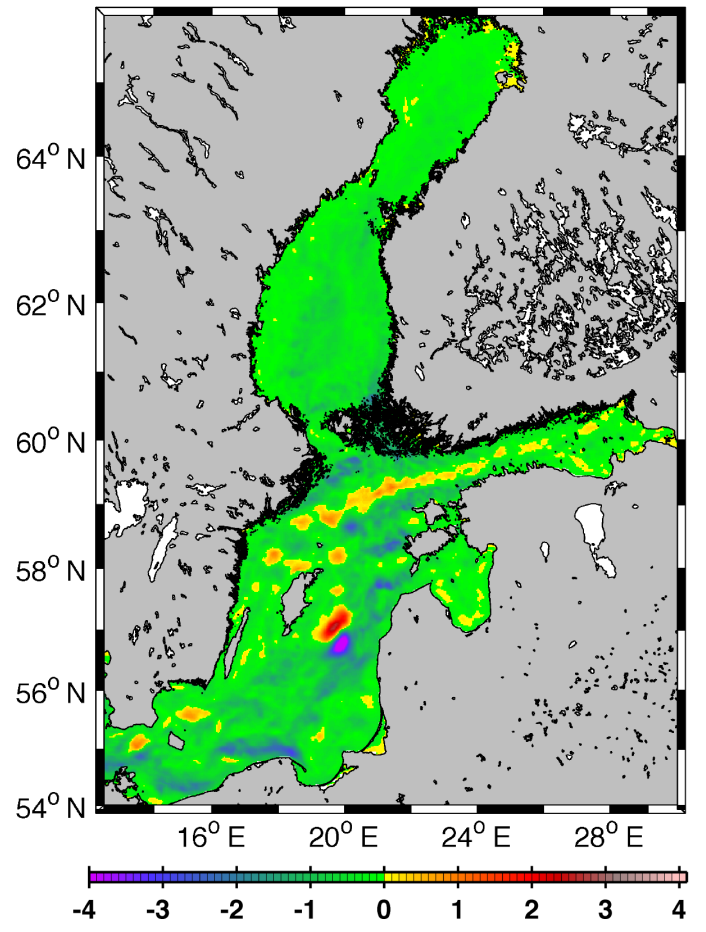

Figure 2. Differences in power driving the oceanic surface circulation in units $\mathrm{mW} \mathrm{m}^{-2}$ (calculated as experiment REF - noCW, averaged over the simulated years 1989-1993). Positive (negative) values indicate that more (less) kinetic energy is supplied to the ocean if surface current-wind effects are accounted for.

\subsection{Local effects in upwelling regions}

The previous section showed that current-wind effects reduce the overall net transfer of kinetic energy to the ocean. This mechanism is so dominant that, contrary to our initial expectations, current-wind effects reduce basin-scale diabatic transports.

Figure 4 shows that the effects are not uniform over the whole basin. Locally, and at times during the season cycle, current-wind effects drive - consistent with initial expectations - reduced SSTs in summer. Intriguingly this applies especially to what Lehmann et al. (2012) dubbed the Baltic's "most favourable upwelling region" off the southernmost coast of Sweden, off Karlshamn and off the Kalmarsund (marked by the magenta ellipse in Fig. 4). An analysis of simulated local air-sea heat fluxes in this region reveals that current-wind effects increase the heat supplied to the ocean by 1 to $5 \mathrm{~W} \mathrm{~m}^{-2}$ (compared to a basin-averaged $d e$ crease of $\approx 5 \mathrm{~W} \mathrm{~m}^{-2}$ ). This indicates that locally - indeed diabatic heat fluxes must be augmented. In order to understand the underlying mechanisms we investigate winds and currents on the southernmost coast of Sweden. The winds blowing over the ocean's surface in these regions are according to Fig. 5 not peculiar: winds in July are typically southwesterly with the only irregularities being that (1) the winds 


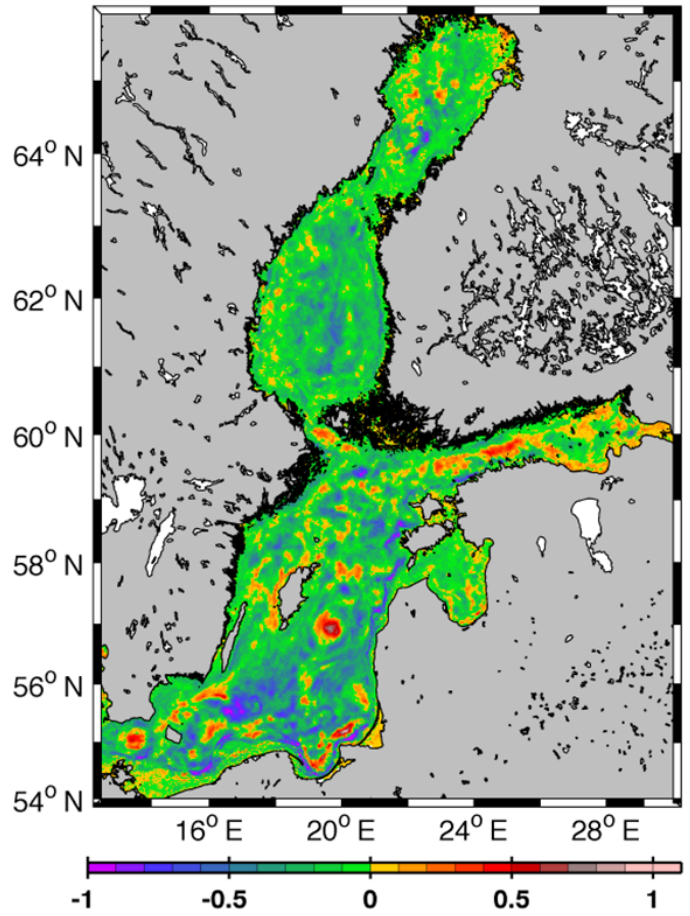

Figure 3. Surface mixed layer depths (as defined by Large et al., 1994, their Eq. 21) differences in units $m$ (calculated as experiment REF - noCW, climatological July based on the simulation period 1989-1993). Positive (negative) values indicate a surface mixed layer that is deepened (shallowed) when surface current-wind effects are accounted for.

are stronger over the sea than on land (and its wake) where surface roughness and associated drag is enhanced, and that (2) the winds' persistency decreases as they travel in a northeastward direction (not shown). What is however peculiar in the region is the distinct anticyclonic circulation in Fig. 6: the currents follow the Swedish coastline on its way to the east and return westwards some 10 nautical miles offshore. These two eastward-westward branches are rather persistent and follow closely the topography (Fig. 7). Consistent with our initial considerations, we find that the winds blowing over this coastal anti-cyclonic circulation yield additional upwelling. Expressed as a climatological Ekman pumping representative for July, the current-wind effects cause an additional local upwelling of $0.2 \mathrm{~m} \mathrm{day}^{-1}$ (Fig. 8). This increase in Ekman pumping is reflected in reduced SSTs (magenta ellipse in Fig. 4).

\section{Discussion}

Our numerical twin experiment yields results that are apparently inconsistent with our initial theoretical considerations (Sect. 1). Based on the persuasive sketch of Martin and Richards (2001) (their Fig. 7), we expected that a proper rep-

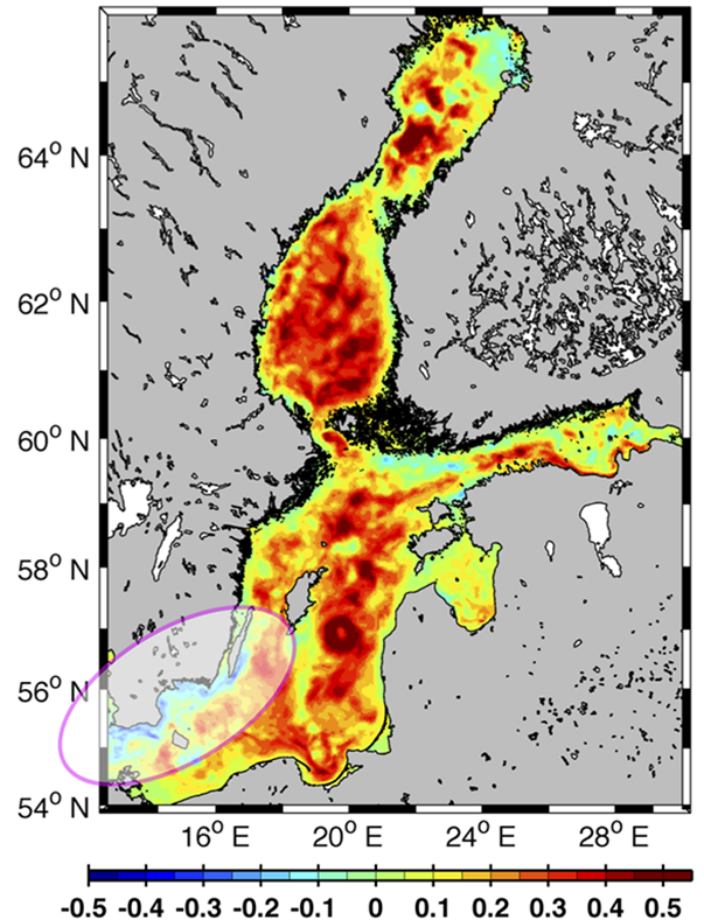

Figure 4. Simulated sea surface temperature differences in units $\mathrm{K}$ (calculated as experiment REF - noCW, climatological July based on simulated years 1989-1993). The magenta ellipse encompasses a region off southern Sweden where surface current-wind effects cool the surface.

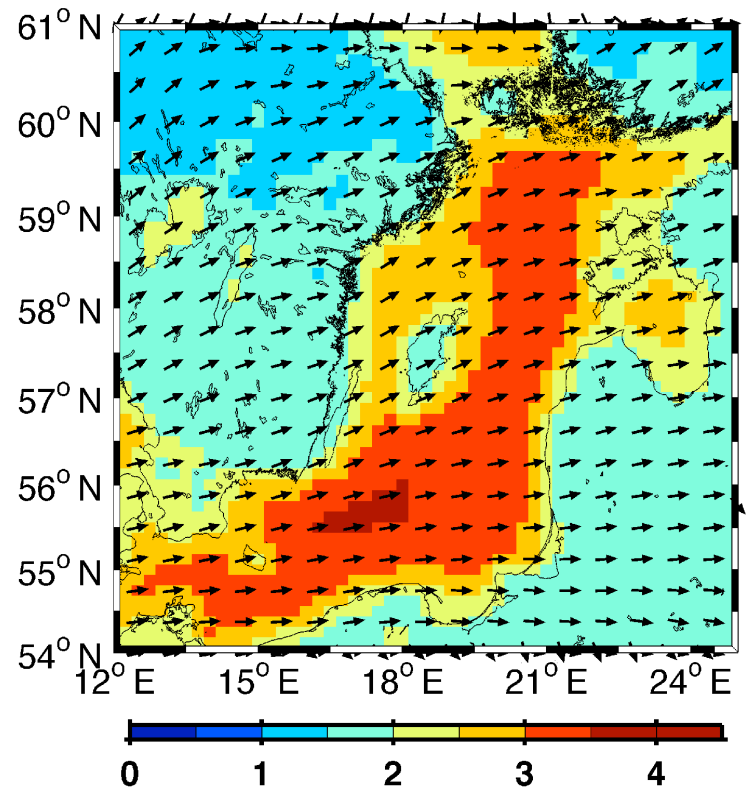

Figure 5. July climatology of the $10 \mathrm{~m}$ winds driving the simulations. The calculation is based on 1989-1993 3-hourly snapshots of RCA3 (Sect. 2.1). The arrows show the direction of the winds. The colour denotes the speed in units $\mathrm{m} \mathrm{s}^{-1}$. 


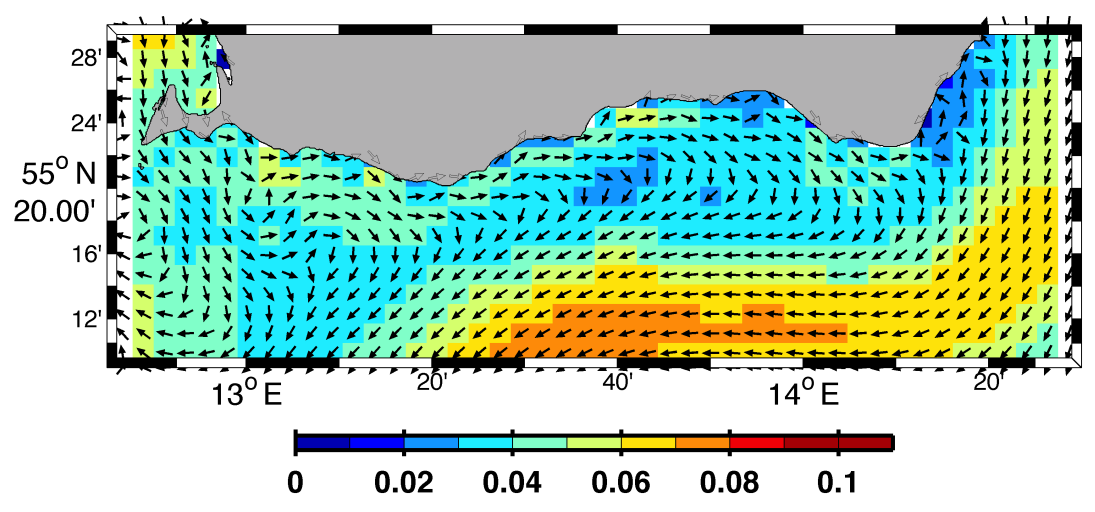

Figure 6. Surface circulation off the southernmost coast of Sweden in summer (climatological July calculated from model output comprising the years 1989 to 1993). The arrows show the direction of the currents. The colour denotes the speed in units $\mathrm{m} \mathrm{s}^{-1}$.

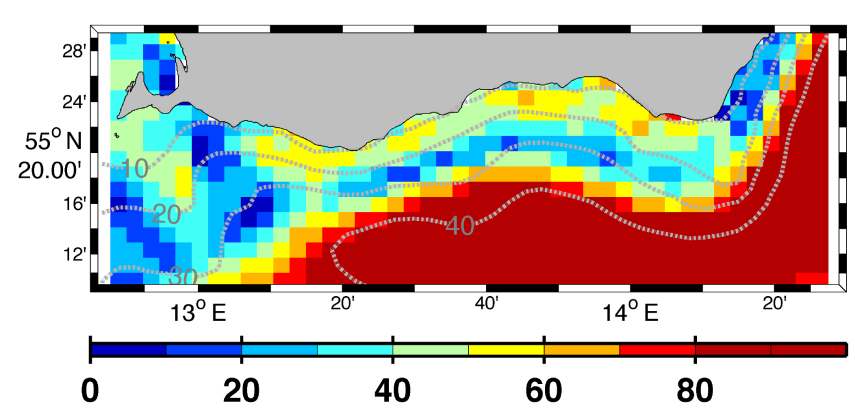

Figure 7. Persistency of surface currents and topography. The colour denotes the persistency of currents defined as the ratio between vector and scalar mean speeds corresponding to climatological July in units \% (cf. Dietze et al., 2014, their Eq. 15). The grey, dashed contours refer to isobaths with $10 \mathrm{~m}$ spacing.

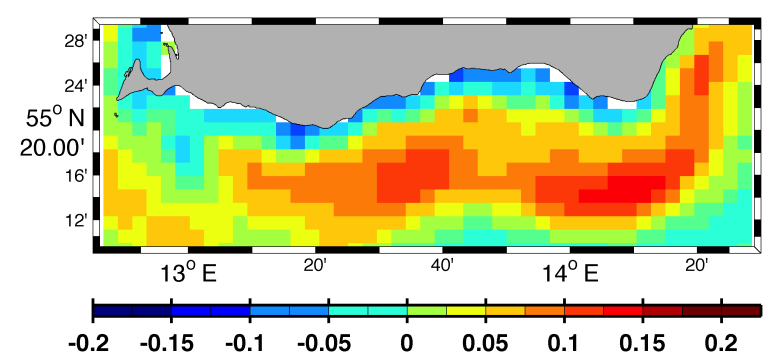

Figure 8. Ekman pumping effected by current-wind interaction (calculated as the difference between experiment REF - noCW; climatological July based on simulated years 1989-1993) in units $\mathrm{m} \mathrm{day}^{-1}$. Positive values denote additional upwelling.

resentation of surface current-wind effects will increase diabatic transport. What we find on a basin scale, however, is the contrary and we get apparently less diapycnal mixing. In Sect. 3.1 we reconciled this inconsistency by an argumentation based on energy supply: when surface current-wind effects are accounted for, less energy is transferred to the ocean (cf. Fig. 2).
An equivalent explanation can be put forward based on wind stress: the climatological, basin-scale wind stress received by the ocean is, on average, less in the configuration, which accounts for surface current-wind effects, than in the simulation that does not account for this effect (not shown). Here, again, the explanation is associated with the fact that, (even) on a rotating planet, the oceanographic response to wind forcing is typically enhanced surface flow in the direction of the wind (in addition to a perpendicular component). If accounted for in the calculation of wind stress, this would reduce the stress acting on the ocean. Somewhat unexpected, this reduction in wind stress and associated reduction in wind-driven up- and downwelling prevails the eddywind effect. This however holds only for averages in time and space. Locally, and at times, the increased horizontal stress inhomogeneity can drive additional Ekman pumping. We calculated that maximum climatological values peak at $0.2 \mathrm{~m} \mathrm{~d}^{-1}$ on the southern coast of Sweden. This drives, as initially expected, indeed additional diabatic fluxes, as is indicated by pronounced SST anomalies (particularly in summer). It is noteworthy, however, that the magnitudes of actual vertical velocities calculated from daily averages are unexpectedly small compared to Ekman velocities diagnosed from the wind stress. This mismatch between Ekman pumping calculated from the wind stress and actual vertical velocities suggests that some preconditions mandatory for the applicability of the Ekman theory are violated. Among these preconditions that are not met are (1) the assumption that boundaries have no effect (i.e. Ekman theory applies only to a waterbody of infinite extent in all three spacial dimensions) - a certainly overoptimistic assumption in the shallow marginal Baltic Sea. (2) The theory assumes a viscosity that is constant with depth - an assumption certainly violated given that the KPP boundary layer parameterization (Large et al., 1994), which is applied in our simulations, has been specifically designed to reproduce observed nonconstant vertical profiles of diffusivities and viscosities. 
Our model results show that accounting for current-wind effects does not drive any additional near-surface net diapycnal transport on a basin-scale. This is somewhat unexpected because our initial theoretical considerations suggested increased wind-induced upwelling and downwelling events (which - in combination with air-sea buoyancy fluxes - would have resulted in net diapycnal transports). This does not imply that current-wind effects are irrelevant. It merely means that the physically less plausible formulation of not accounting for them does not necessarily underestimate diapycnal fluxes because antagonistic effects are at play: on the one hand surface current-wind effects reduce the kinetic energy supply to the ocean, and on the other hand these effects increase wind stress curl and associated vertical transports. Getting more specific, we can now (based on our analysis of air-sea heat fluxes, kinetic energy supply, surface mixed layer dynamics, SST, surface currents, and winds) pigeonhole ocean circulation model configurations into the following classes:

- Coarse and no current-wind effect: Eddy-permitting Baltic Sea model configurations have only recently become computationally feasibly. Older configurations resolve neither eddies nor small-scale near-coastal circulation patterns. Additional simplifications in some of these configurations comprise the neglect of currentwind effects in the wind-stress calculation. Insights gained in the present study suggest that these configurations (1) overestimate the supply of kinetic energy to the ocean and (2) underestimate the horizontal inhomogeneity of the wind stress and its associated Ekman pumping. As these spurious effects oppose one another the sign of the net effect on diapycnal transport is unclear. It is, however, evident that this class of configurations misses the substantial modulation of upwelling by the interaction of persistent near-coastal current features with the winds at major upwelling sites.

- Coarse and current-wind effect: Some of the older coarse-resolution model configurations may include the representation of surface current-wind effects in their calculation of the wind stress. These configurations do not overestimate the supply of kinetic energy to the extent the latter class does. The overall Ekman pumping is however - owed to the coarse resolution - still underestimated. Thus we speculate that the net effect on basin-scale is an underestimation of diapycnal fluxes. As concerns major upwelling sites, the modulating effects of persistent small-scale topographically steered circulation (as described above) are not resolved.

- Eddies and no current-wind effect: Most contemporary model configurations strive to resolve the mesoscale. However, not all explicitly account for current-wind effects. Among the reasons for the neglect are the following:
(1) Increased computational performance (in cases where the calculation of the wind stress is performed by a coupler between the ocean and the atmospheric winds, these couplers can significantly increase wall-clock times).

(2) Pragmatic avoidance of subtleties associated with the coupling: eddy-rich configurations are inherently non-linear. Taking current-wind effects into account adds another level of non-linearity. The solutions become strongly dependent on the coupling time step, and the choice is between small time steps requiring high computational costs and larger time steps resulting in diverging solutions.

(3) The notion that the effect of surface currents are neglected because they are typically so much smaller than wind velocities. The results in Sect. 3 suggest that these configurations overestimate the supply of energy and momentum supplied to the ocean. In turn, the energy available for diapycnal mixing is unrealistically high. This effect, however, is partly counterbalanced by spuriously reduced Ekman pumping. As regards major upwelling sites, these configurations resolve the near-coastal, persistent small-scale circulation. Its local effect on Ekman pumping is, however, not considered.

- Eddies and current-wind effect: The supply of kinetic energy and momentum to the ocean is not overestimated. Small-scale circulation patterns modulate the wind-induced up- and downwelling. The agreement with SST data is extraordinarily good (cf. Figs. 8, 9, and 10 in Dietze et al., 2014, which show a comparison of REF with data).

\section{Summary and conclusion}

We set out to explore effects of surface current-wind interaction in an eddy-rich general ocean circulation simulation of the Baltic Sea at a time where the resolution of mesoscale surface currents in the Baltic has just about become computationally feasible. Triggered by theoretical considerations on individual eddies (Dewar and Flierl, 1987; Martin and Richards, 2001), we expected to find enhanced basin-scale diabatic transports effected by increased wind stress curl and associated Ekman pumping. Contrary to our expectations we find in our general ocean circulation model simulations that the major, prevailing effect of accounting for current-wind interaction is a large-scale reduction in the overall net supply of kinetic energy to the ocean. This reduction of energy supply limits the amount of energy that is available for mixing dense water upwards (and light water downward). As a consequence of the reduced diabatic mixing we find shallower surface mixed layer depths and large-scale surface warming (cooling) in summer (winter). 
Locally, however, the pattern is reversed and apparently in line with our initial considerations: an analysis of winds and currents around the southernmost coast of Sweden (off Karlshamn and off the Kalmarsund) reveals a relatively persistent anti-cyclonic circulation. Consistent with the argumentation of Dewar and Flierl (1987) and Martin and Richards (2001) concerning the effects of surface currents on Ekman upwelling, these coastal anti-cyclonic surface currents affect an additional upwelling that is dominant and persistent enough to drive distinct local SST anomalies in summer. The climatological magnitude of these anomalies is around $0.5 \mathrm{~K}$ and as such is prone to affect the formation of sea fog in those regions. Yet another effect of the upwelling of cold subsurface waters is associated with strong vertical gradients in nutrients such as phosphate and nitrate, which are essential for autotrophic growth. During summer the sunlit surface of the Baltic is typically depleted in these nutrients and all phytoplankton growth is impeded. Upwelling of cold subsurface waters which are enriched in nutrients thus drives additional phytoplankton growth.

We conclude that surface current-wind effects are significant. Basin-scale effects correspond to $\approx 0.1 \mathrm{~K}$. Local climatological effects may be reversed and peak at $\approx 0.5 \mathrm{~K}$. The timing in summer, when oligotrophic conditions prevail, in combination with the substantial magnitude suggests that local current-wind effects exert significant control on the complex biogeochemical cycling of the Baltic Sea.

\section{Data availability}

The model configuration MOMBA 1.1 is available at http://www.baltic-ocean.org/?page_id=75 or http://thredds.geomar.de/thredds/catalog/open_access/ dietze_et_al_2014_gmdd/catalog.html. The model output is archived at http://thredds.geomar.de/thredds/catalog/open_ access/dietze_loeptien_2016_osd/catalog.html.

Acknowledgements. This is a pilot study pioneering ultrahigh-resolution work proposed in the Sonderforschungsbereich 754 (relating to subprojects B9, A2, B1) funded by Deutsche Forschungsgemeinschaft. We are grateful to Andreas Oschlies for providing essential long-term support. Integrations were performed on the FB2/BM compute clusters weil.geomar.de and wafa.geomar.de located at the GEOMAR Helmholtz Centre for Ocean Research, west shore campus, Kiel, Germany. We acknowledge help from Kai Grunau in setting up and maintaining these clusters. We appreciate discussions with Robinson Hordoir, SMHI, Sweden. We acknowledge helpful comments by two anonymous reviewers. This work is based on efforts from the Modular Ocean Model community (http://mom-ocean.org). Thank you for sharing your work so freely!

Edited by: A. Sterl

Reviewed by: two anonymous referees

\section{References}

Carstensen, J., Andersen, J. H., Gustafsson, B. G., and Conley, D. J.: Deoxygenation of the Baltic Sea during the last century, PNAS, 111, 5628-5633, 2014.

Dewar, W. K. and Flierl, G. R.: Some Effects of the Wind on Rings, J. Phys. Oceanogr., 17, 1653-1667, 1987.

Dietze, H. and Kriest, I.: ${ }^{137}$ Cs off Fukushima Dai-ichi, Japan model based estimates of dilution and fate, Ocean Sci., 8, 319332, doi:10.5194/os-8-319-2012, 2012.

Dietze, H. and Löptien, U.: Revisiting "nutrient trapping” in global coupled biogeochemical ocean circulation models, Global Biogeochem. Cy., 27, 265-284, 2013.

Dietze, H. and Oschlies, A.: Modeling abiotic production of apparent oxygen utilisation in the oligotrophic subtropical North Atlantic, Ocean Dynam., 55, 28-33, 2005.

Dietze, H., Löptien, U., and Getzlaff, K.: MOMBA 1.1 - a highresolution Baltic Sea configuration of GFDL's Modular Ocean Model, Geosci. Model Dev., 7, 1713-1731, doi:10.5194/gmd-71713-2014, 2014.

Duhaut, T. H. A. and Straub, D. N.: Wind stress dependence on ocean surface velocity: Implications for mechanical energy input to ocean circulation, J. Phys. Oceanogr., 36, 202-211, 2006.

Eden, C. and Dietze, H.: Effects of mesoscale eddy/wind interactions on biologic new production and eddy kinetic energy, J. Geophys. Res., 114, C05023, doi:10.1029/2008JC005129, 2009.

Fairall, C. W., Bradley, E. F., Hare, J. E., Grachev, A. A., and Edson, J. E.: Bulk parameterization of air sea fluxes: updates and verification for the COARE algorithm, J. Clim., 16, 571-591, 2003.

Fennel, W., Seifert, T., and Kayser, B.: Rossby radii and phase speeds in the Baltic Sea, Cont. Shelf Res., 11, 23-36, 1991.

Griffies, S. M., Yin, J., Durack, P. J., Goddard, P., Bates, S. C., Behrens, Bentsen, M., Bi, D., Biastoch, A., Böning, C. W., Bozec, A., Chassignet, E., Danabasoglu, G., Danilov, S., Domingues, C. M., Drange, Farneti, R., Fernandez, Greatbatch, R. J., Holland, D. M., Ilicak, M., Large, W. L., Lorbacher, K., Lu, J., Marsland, S. J., Mishra, Nurser A. J. G., Salas y Mélia, D., Palter, J. B., L. S., Bonita, Schröter, J., Schwarzkopf, F. U., Sidorenko, D., A.-M.Treguier, Tseng, Y.-h., Tsujino, H., Uotila, P., Valcke, S., Voldoire, A., Wang, Q., Winton, M., and Zhang, $\mathrm{X}$.: An assessment of global and regional sea level for years 1993-2007 in a suite of interannual CORE-II simulations, Ocean Modell., 78, 35-89, 2014.

HELCOM: Ensuring Safe Shipping in the Baltic, edited by: Stankiewicz, M. and Vlasov, N., Helsinki Comission, Helsinki, 2009.

Hordoir, R., Dieterich, C., Basu, C., Dietze, H., and Meier, H. E. M.: Freshwater outflow of the Baltic Sea and transport in the Norwegian current: A statistical correlation analysis based on a numerical experiment, Cont. Shelf Res., 64, 1-9, doi:10.1016/j.csr.2013.05.006, 2013.

Hordoir, R., Axell, L., Löptien, U., Dietze, H., and Kutzenov, I.: Influence of Sea Level Rise on the Dynamics of Salt Inflows in the Baltic Sea, J. Geophys. Res.-Ocean., 120, 6653-6668, doi:10.1002/2014JC010642, 2015. 
Hsu, S. A.: A Dynamic Roughness Equation and Its Application to Wind Stress Determination at the Air-Sea Interface, J. Phys. Oceanogr., 4, 116-120, 1973.

Hsu, S. A.: On the log-linear wind profile and the relationship between shear stress and stability characteristics over the sea, Bound.-Lay. Meterol., 6, 509-514, 1974.

Jedrasik, J., Cieslikiewicz, W., Kowalewski, M., Bradtke, K., and Jankowski, A.: 44 years hindcast od the sea level and circulation in the Baltic Sea, Coast. Engin., 55, 849-860, 2008.

Jones, C. G., Willen, U., Ullerstig, A., and Hansson, U.: The Rossby Centre Regional Atmospheric Climate Model Part I: Model climatology and performance for the present climate over Europe, Ambio, 33, 199-210, 2004.

Kähler, P., Oschlies, A., Dietze, H., and Koeve, W.: Oxygen, carbon, and nutrients in the oligotrophic eastern subtropical North Atlantic, Biogeosciences, 7, 1143-1156, doi:10.5194/bg-7-11432010, 2010.

Kara, A. B., Metzger, E. J., and Bourassa, M. A.: Ocean current and wave effects on wind stress drag coefficient over the global ocean, Geophys. Res. Lett., 34, L01604, doi:10.1029/2006GL027849, 2007.

Large, W.: Surface fluxes for practioners of global ocean data assimilation, in: Ocean weather and forecasting, edited by: Chassignet E. and Verron J., Springer, Heidelberg, 229-270, 2006.

Large, W. G. and Yeager, S. G.: Diurnal to decadal global forcing f/or ocean and sea-ice models: The data sets and flux climatologies, Rep. NCAR/TN-460+STR, Natl. Cent. Atmos. Res., Boulder, Colorado, 105 pp., 2004.

Large, W. G., McWilliams, J. C., and Doney, S. C.: Oceanic vertical mixing - A review and a model with nonlocal boundary-layer parameterization, Rev. Geophys., 32, 363-403, 1994.

Ledwell, J. R., McGillicuddy, D. J., and Anderson, L. A.: Nutrient flux into an intense deep chlorophyll layer in a mode-water eddy, Deep-Sea Res. Pt. II, 55, 1139-1160, doi:10.1016/j.dsr2.2008.02.005, 2008.

Lehmann, A. and Myrberg, K.: Upwelling in the Baltic Sea - A review, J. Mar. Syst., 74, S3-S12, doi:10.1016/j.jmarsys.2008.02.010, 2008.

Lehmann, A., Myrberg, A., and Höflich, K.: A statistical approach to coastal upwelling in the Baltic Sea based on the analysis of satellite data for 1990-2009, Oceanologica, 53, 369-393, 2012.

Leppäranta, M. and Myrberg, K.: Physical oceanography of the Baltic Sea, ISBN 978-3-540-79702-9, Springer, 2009.

Liu, N., Eden, C., Dietze, H., Wu, D., and Lin, X.: Model-based estimates of the heat budget in the East China Sea, J. Geophys. Res., 115, C08026, doi:10.1029/2009JC005869, 2010.

Löptien, U. and Meier, H. E. M.: The influence of increasing water turbidity on the sea surface temperature in the Baltic Sea: A model sensitivity study, J. Mar. Syst., 88, 323-331, 2011.

Löptien, U., Mårtensson, S., Meier, H. E. M., and Höglund, A.: Long-term characteristics of simulated ice deformation in the Baltic Sea (1962-2007), J. Geophys. Res.-Ocean., 118, 801-815, 2013.

Martin, A. P. and Richards, K. J.: Mechanisms for the vertical nutrient transport within a North Atlantic mesoscale eddy, Deep-Sea Res. Pt. II, 48, 757-773, 2001.

McGillicuddy, D. J., Anderson, L. A., Bates, N. R., Bibby, T., Buesseler, K. O., Carlson, C. A., Davis, C. S., Ewart, C., Falkowski, P. G., Goldthwait, S. A., Hansell, D. A., Jenkins, W. J., John- son, R., Kosnyrev, V. K., Ledwell, J. R., Li, Q. P., Siegel, D., and Steinberg, D. K.: Eddy/Wind Interactions Stimulate Extraordinary Mid-Ocean Plankton Blooms, Science, 316, 1021-1026, doi:10.1126/science.1136256, 2007.

Meier, H. M. and Faxen, T.: Performance analysis of a multiprocessor coupled ice-ocean model for the Baltic Sea, J. Atmos. Ocean. Technol., 19, 114-124, 2002.

Meier, H. E. M., Döscher, R., Coward, A. C., Nycander, J., and Döös, K.: RCO-Rossby Centre regional Ocean climate model: model description (version 1.0) and first results from the hindcast period 1992/93, SMHI Reports Oceanogr., 23, 1-102, 1999.

Meier, H. E. M., Hordoir, R., Andersson, A. C., Dieterich, C., Eilola, K., Gustafsson, B. G., Höglund, A., and Schimanke, S.: Modeling the combined impact of changing climate and changing nutrient loads on the Baltic Sea environment in an ensemble of transient simulations for 1961-2099, Clim. Dynam., 39, 2421-2441, 2011.

Köhl, A., Stammer, D., and Cornuelle, B.: Interannual to Decadal Changes in the ECCO Global Synthesis, J. Phys. Oceanogr., 37, 313-337, 2007.

Kuznetsov, I., Neumann, T., and Burchard, H.: Model study on the ecosystem impact of a variable $\mathrm{C}: \mathrm{N}: \mathrm{P}$ ratio for cyanobacteria in the Baltic Proper, Ecol. Modell., 219, 107-114, 2008.

Neumann, T., Eilola, K., Gustafsson, B., Müller-Karulis, B., Kuznetsov, I., Meier, H. E. M., and Savchuk, O. P.: Extremes of Temperature, Oxygen and Blooms in the Baltic Sea in a Changing Climate, AMBIO, 41, 574-585, 2012.

Olita, A., Iermano, I., Fazioli, L., Ribotti, A., Tedesco, C., Pessini, F., and Sorgente, R.: Impact of currents on surface flux computations and their feedback on dynamics at regional scales, Ocean Sci., 11, 657-666, doi:10.5194/os-11-657-2015, 2015.

Oschlies, A., Dietze, H., and Kähler, P.: Salt-finger driven enhancement of upper ocean nutrient supply, Geophys. Res. Lett., 30, 2204, doi:10.1029/2003GL018552, 2003.

Roquet, F., Wunsch, C., and Madec, G.: On the Patterns of WindPower Input to the Ocean Circulation, J. Phys. Oceanogr., 41, 2328-2342, 2011.

Samuelsson, P., Jones, C. G., Willen, U., Ullerstig, A., Gollvik, S., Hansson, U., Jansson, C., Kjellström, E., Nikulin, G., and Wyser, K.: The Rossby Centre Regional Climate model RCA3: model description and performance, Tellus A, 63, 4-23, 2011.

Smith, S. D. and Banke, E. G.: Variation of the sea surface drag coefficient with wind speed, Q. J. R. Meterol. Soc., 101, 665673, 1975.

Stammer, D., Ueyoshi, K., Köhl, A., Large, W. G., Josey, S. A., and Wunsch, C.: Estimating air-sea fluxes of heat, freshwater, and momentum through global ocean data assimilation, J. Geophys. Res., 109, C05023, doi:10.1029/2003JC002082, 2004.

Stommel, H.: A survey of ocean current theory, Deep-Sea Res. Pt. I, 4, 149-184, 1957.

Taylor, G.: Skin friction of the wind on the earth's surface, Proc. Roy. Soc. London, A92, 196-199, 1916.

Tuovinen, P., Kostilainen, V., and Hämäläinen, A.: Studies on Ship casualties in the Baltic Sea 1979-1984, Baltic Sea Environ. Proc., 11, 1-88, 1984.

Uppala, S. M., Kallberg, P. W., Simmons, A. J., Andrae, U., Bechtold, V. D., Fiorino, M., Gibson, J. K., Haseler, J., Hernandez, A., Kelly, G. A., Li, X., Onogi, K., Saarinen, S., Sokka, N., Allan, R. P., Andersson, E., Arpe, K., Balmaseda, M. A., Beljaars, 
A. C. M., van de Berg, L., Bidlot, J., Bormann, N., Caires, S., Chevallier, F., Dethof, A., Dragosavac, M., Fisher, M., Fuentes, M., Hagemann, S., Holm, E., Hoskins, B. J., Isaksen, L., Janssen, P. A. E. M., Jenne, R., McNally, A. P., Mahfouf, J.- F., Morcrette, J.-J., Rayner, N. A., Saunders, R. W., Simon, P., Sterl, A., Trenberth, K. E., Untch, A., Vasiljevic, D., Viterbo, P., and Woollen, J.: The ERA-40 re-analysis, Q. J. Roy. Meteorol. Soc., 131, 2961-3012, 2005.
Xu, Y. and Scott, R. B.: Subtleties in forcing eddy resolving ocean models with satellite wind data, Ocean Modell., 20, 240-251, 2008.

Zhai, X. and Greatbatch, R.: Wind work in a model of the northwest Atlantic Ocean, Geophys. Res. Lett., 34, L04606, doi:10.1029/2006GL028907, 2007. 